\title{
La nave blanca (Roberto Rossellini, 1941) que sana las camisas negras
}

\author{
Ludovico LONGHI \\ Departamento de Comunicación Audiovisual \\ Universitat Autònoma de Barcelona \\ ludovico.longhi@uab.cat
}

\begin{abstract}
RESUMEN
1941, a medida que los bombardeos norteamericanos causan destrucción y muerte, la población se da cuenta de que el gobierno fascista había trágicamente mentido: no existe una guerra rápida y sin pena alguna. Tras el frenesí propagandístico de los documentales de exaltación militar Ali fasciste (Fernando Cerchio, 1941), directores y trabajadores de Cinecittà frenan su apoyo a la agresiva política militar. El ministro de Cultura Popular Alessandro Pavolini aprueba de inmediato la financiación de una serie de películas que infundan una visión de la guerra como una condición serenamente aceptada por los soldados. Se entiende proponer una nueva forma de heroísmo que aleja las actitudes beligerantes y premia la solidaridad, la abnegación y el sacrificio. El presente trabajo quiere analizar cómo en este nuevo curso, y particularmente a partir de La nave bianca (1941, primer largometraje de Rossellini), se introducen los primeros gérmenes de la estética neorrealista.
\end{abstract}

Palabras clave: La nave blanca, Roberto Rossellini, fascismo, propaganda militar.

\section{The White Ship (Roberto Rossellini, 1941) that heals the Blackshirts}

\begin{abstract}
As US bombardments caused death and destruction, common people realized that the fascist ads of a quick war without penalty were a tragic governmental lie. After the propagandist frenzy of military exaltation documentaries like Ali fasciste (Fernando Cerchio, 1941), directors and employees of Cinecittà held back their support for an aggressive military policy. In 1941 Pavolini, the Popular Culture Minister, approved immediately funding for a series of films that instilled a vision of war as a condition serenely accepted by soldiers. It was proposing a new form of heroism that alienated the belligerent attitudes and rewarded solidarity, selflessness and sacrifice. This paper wants to analyse how this new course, and in particular The White Ship (1941, the first feature of Rossellini), contained the first neorealist aesthetic seeds.
\end{abstract}

Keywords: The White Ship, Roberto Rossellini, Fascism, Military Propaganda. 


\section{1. «Aprendí el modo documental de observar y analizar con mis primeros cortos» (Rossellini 2006: 88)}

Dejo a otro decidir si el neorrealismo se ha dado a conocer de forma más universal con Roma città aperta. Yo creo que el origen de la nueva sensibilidad es anterior. Pienso en un grupo de documentales novelizados, entre los cuales está mi primer largometraje $\mathrm{La}$ nave bianca. (Verdone y Rossellini 1952: 7-8)

Su primera esposa Marcella De Marchis lo ha dejado muy claro: ni ella ni Roberto eran fascistas. Como representantes de la alta burguesía romana salían con los hijos del duce, Bruno y Vittorio Mussolini: dos personas muy amables que sufrían el peso del apellido y que nunca hablaban de política (Faldini y Fofi 2009: 124). Sin embargo, la primerísima incursión en el mundo del cinematógrafo del autor de Roma ciudad abierta (la obra maestra neorrealista de 1945) se inscribe dentro de la producción de propaganda fascista. Sus primeros tres largometrajes, La nave bianca (1941), Un pilota ritorna (1942) y L'uomo della croce (1943), representan respectivamente tres encargos del Centro Cinematográfico del Ministerio de la Marina, de la Aviación y del Ejército. La aparente contradicción abre camino a sugerentes reflexiones sobre la relación entre el régimen y la intelligentsia coeva, entre contexto político y dinámica autoral, etiqueta de producción y poéticas individuales (Zagarrio 2004: 192). En definitiva, reclama una reconsideración analítica de la filmografía italiana realizada durante la dictadura: un corpus rico, variado y culpablemente casi olvidado. Muy probablemente (y como intentaremos verificar), la obra rosselliniana durante y después de la guerra responde a la misma necesidad de exploración lírica y espiritual. Explicita la búsqueda de una verdad histórica y personal más profunda y transversal de la contingencia histórica. Al joven Rossellini no le interesaba la política, no había hecho el servicio militar, ni se había matriculado en la universidad. Tenía fuertes inquietudes intelectuales que (ya desde entonces) no sabía encasillar en una dirección o disciplina concreta. Su hermano Renzo había conseguido dirigir los ímpetus artísticos familiares en dirección musical, pero él todavía no se había decidido. Venía de una familia de constructores y su padre, precisamente, había construido el cine Barberini (asegurando a toda su familia la posibilidad de entrar gratuitamente). La asidua frecuentación de la sala había regalado al séptimo arte una posición de primacía en la esfera del divertissement. Por este motivo, sus primeras aproximaciones a las técnicas cinematográficas adquirirán todas las connotaciones de experimento lúdico. Estas experiencias no responden directamente a lógicas mercantiles (al menos al principio), sino a necesidades expresivas casi pulsionales (Rondolino 2006: 26): ejercicios de manualidad creativa, una práctica fascinante aprendida cotidianamente como un trabajo menor, más bien escondido, pero máximamente importante...

[...] Mis primeras ejercitaciones han sido unos documentales. Los preparaba con la ayuda y los preciosos consejos de mi hermano Renzo que ya trabajaba como crítico musical y compositor de bandas sonoras. El Prélude à l'après-midi d'un faune no es un ballet visual como podría creer quien no lo ha visto. Es un documento sobre la naturaleza como lo eran Ruscello di Ripasottile y Fantasia sottomarina. Me interesaban la ser- 
piente en el agua, la libélula que volaba. Una sensibilidad minimalista atenta a los elementos pequeños humildes como los perritos de la cubierta de La nave bianca. (Rosse1lini 2006: 92)

Un desempeño fisiológico lo conduce a la realización del Prélude à l'après-midi d'un faune y Daphne, cómplice las ayudas y los consejos de su hermano menor (admirador entusiasta del músico Debussy). Renzo, en efecto, se había diplomado en música y composición en el Conservatorio Santa Cecilia. Había conseguido una plaza de profesor de música en la escuela pública, y contemporáneamente se dedicaba a componer bandas sonoras, entre ellas las de Il signor Max (Mario Camerini, 1937) y La princesa Tarakanova (Fedor Ozep e Mario Soldati, 1938). Así las sugerencias consanguíneas (más que el ejemplo) y las responsabilidades paternas (en 1937 nace Romano, hijo de su primera esposa Marcella De Marchis) convierten la afición de Roberto en su primer empleo:

[...] mi ingreso dentro del cine comercial se ha verificado de forma clandestina. Casi en forma de estraperlo. Todo ocurrió gracias a un gran amigo mío (le quería mucho) que era un guionista de talento: en la época no había muchos, tres o cuatro como mucho. Me consideraba una persona original, no del todo tonto pero un poco raro sí. Me dio la posibilidad de trabajar como negro: me pagaba tres mil liras por guion. Con las mil anticipadas (una cantidad considerable) vivía un mes. Cuando la suma se estaba agotando acababa de escribir la primera parte así me daba otras mil, cuando estaba con el agua al cuello acababa la segunda parte. En total tardaba dos días. (Rossellini apud Savio 1979: 964)

\section{Los animales y la propaganda: David y Goliat}

Divagación y necesidad, pero en el fondo siempre un motu afectivo. El amigo en cuestión era Aldo Vergano (Baldelli 1972: 252) futuro director del film de propaganda Quelli della Montagna (1942) y seguidamente del antifascista Il sole sorge ancora (1946). Muy significativo parece este apadrinamiento de una personalidad que rompe cualquier intento maniqueo de asignar juicios estéticos únicamente bajo la perspectiva ideológica. Efectivamente Rossellini colabora, como negro, al guion de La fossa degli angeli (Carlo Ludovico Bragaglia, 1937), un filme perdido que narra la dura vida de los trabajadores del mármol. Este, según las recensiones coevas, recordaba el estilo documental de Acciaio (Walter Ruttmann, 1929): la misma idea de utilizar localizaciones auténticas, los personajes reales en una trama siempre más distante de cualquier dramaturgia efectista (Rondolino 2006: 33). Una línea poética que persigue en su siguiente colaboración cinematográfica: la película Luciano Serra pilota (Goffredo Alessandrini, 1938). Se trata de una superproducción (al estilo del contemporáneo Scipione l'Africano, de Carmine Gallone) promovida y supervisada por Vittorio Mussolini, que quería celebrar paralelamente la inauguración de Cinecittà y la aventura colonial en África. Sin embargo, a pesar de las altisonantes premisas, la narración se construye alrededor de un personaje (interpretado por Amedeo Nazzari)... 
[...] capaz de interpretar un héroe cotidiano, cercano a la gente común. Un personaje que se expresa con un lenguaje directo, lo más anti heroico posible, que puede comunicar pasiones y estados de ánimo con gestos secos. Luciano Serra es una película italiana nueva porque consigue realizar, como pocas otras del periodo, una total identificación entre espectador y protagonista. [...] Encarna las características de una precisa identidad social que rechaza los señuelos del mundo espectacular y mediático, seductor pero vacío, mentiroso y animado únicamente por las lógicas del beneficio. Finalmente, en plena guerra, relativiza sus anteriores fracasos asumiendo su rol definitivo de padre y aviador en el momento del sacrificio. (Mosconi 2006: 242)

La colaboración rosselliniana al proyecto libera al joven cineasta del anonimato. Paralelamente la cercanía al entourage del hijo del duce lo promueve como coguionista, ayudante de dirección y director de la segunda unidad de rodaje. Junto con Umberto Scarpelli había seguido Alessandrini en Etiopía, donde rueda algunas secuencias documentales y escenas de masa. No existen pruebas ciertas de sus concretas aportaciones a la edición definitiva de la película (el inconmensurable volumen de metraje ha sido montado por el futuro director Giorgio Simonelli). Según Sergio Amidei (el testimonio más plausible), mientras que Alessandrini realizaba en África las escenas de guerra, Rossellini se ocupaba de los interiores en Cinecittà, supervisado por Vittorio Mussolini. Robaba paulatinamente la película al director titular y configuraba su método particular (Amidei apud Faldini y Fofi 2009: 102). Un estilo propio que continuaba experimentando en sus cortometrajes, en plena autonomía. Había transformado su casa de Ladispoli (en la costa romana) en un pequeño taller cinematográfico: practicaba la pesca submarina y luego filmaba a sus «víctimas». En 1939 dentro del acuario de su jardín realiza Fantasia sottomarina, cortometraje (producido por INCOM y comisionado por la empresa de congelados Genepesca) que narra la rebelión de un pequeño besugo a las tiranías de un pulpo despótico. El año siguiente repite la operación con Il ruscello di Ripasottile: esta vez a los pececitos se añaden animales del bosque y del campo. Se trata de una fábula al estilo de Esopo que retoma la alegoría de una comunidad pacífica, improvisadamente amenazada por el villano de turno, en este caso las truchas. La misma fórmula se repite en La vispa Teresa y en Il tacchino prepotente. En este último caso el pavo protagonista es presentado como el dictador de la granja. Una parodia del mismo Mussolini, según el modelo literario Rebelión en la granja de Orwell (donde el cerdo Napoleón satirizaba la figura de Stalin). Alegoría de un tirano que (justo en los mismos meses de estreno del corto y ya en proximidad de la declaración de guerra) celebraba la vis bélica de sus súbditos de forma siempre más pedante e insistente en los noticiarios cinematográficos (Argentieri 2003: 87). Estos cortometrajes al estilo disneyano proponen unos temas simples, lineales, y una técnica minimalista: casi una oposición dialéctica a la grandilocuente propaganda coeva (Rondolino 2006: 44). El pasaje de los cortos zoológicos a los largometrajes con intérpretes humanos, sigue una evolución técnica, temática y poética que configuran ciertas constantes de la obra rosselliniana (Caminati 2012: 43):

Los cortometrajes de Rossellini comparten el mismo tema con sus tres primeros largometrajes [...]. Se trata de la lucha entre David (la pareja de besugos, las mariposas, los animales de la granja; es decir el marinero herido, el piloto capturado, el capellán inde- 
fenso) y Goliat (el Pavo, la niña Teresa, las truchas; es decir la violencia de la guerra tout court, más que un enemigo concreto). Los primeros intentan conservar (contra los otros prepotentes) la serenidad cotidiana otorgada. (Aprà 2010: 87)

\section{Nadie creía que los marineros auténticos lograran sustituir a los actores}

Italia declara la guerra a Francia e Inglaterra el 10 de junio de 1940. El resto de Europa estaba en pleno conflicto desde hacía casi un año (desde septiembre de 1939) y el aparato bélico fascista ya estaba movilizado. Ejército, Aviación y Marina tenían un servicio cinematográfico que proporcionaba material filmado al Istituto Luce (productora regimental de cine noticiarios). Eran documentos que ilustran combates, ruinas, paradas, heroísmos, acciones militares y discursos ardorosos. Imágenes de guerra que se convertían en enérgicos vehículos de propaganda (Rondolino 2006: 39). Se trataba de actualidades cinematográficas o documentales de exaltación militar con títulos altisonantes como Vita e fine della S. Giorgio ${ }^{1}$ (Romolo Marcellini, 1941) y Ali fasciste ${ }^{2}$ (Fernando Cerchio, 1941). En este ámbito el departamento militar más activo pertenecía al Ministerio de la Marina: gran parte del mérito se debía a la pericia cinematográfica del capitán de corbeta Francesco De Robertis. El oficial, con un pasado de exitoso dramaturgo, había experimentado una fórmula narrativa nueva y eficaz en dos textos fílmicos, tanto en Mine alla vista (1940), como en Uomini sul fondo (1941): se trataba de reconstruir episodios de guerra utilizando, como intérpretes, auténticos marineros u oficiales. Normalmente todas las películas de propaganda hacían servir todos los recursos posibles (representativos y narrativos) para suscitar animadversión hacia el enemigo. De Robertis, en cambio, se inspira en un trágico accidente sufrido por la marina inglesa. En junio de 1939 (dos meses antes del principio de la guerra) el submarino Thetis, tras prolongados y desesperados intentos de socorro, había perdido a toda su tripulación:

[...] el episodio había conmovido a la opinión pública de todo el mundo [...]. La curiosidad y el interés por los desesperados tentativos de salvación convencieron al Ministerio de la Marina a apoyar mi proyecto de reconstrucción del evento. La Dirección General de Cinematografía interpuso muchos obstáculos. Las productoras y el ambiente cinematográfico coevo rechazaron la propuesta. Nadie creía que los marineros auténticos lograran sustituir a los actores. (De Robertis 1949: 212)

El filme combina el ritmo trepidante de los acontecimientos con la espectacularidad de la ilustración tecnológica: los escafandros de los buceadores remitían a la ciencia-ficción; las asfixiadas secuencias subacuáticas, la cortina de flúor y la niebla, a una película de misterio. El relato (trasladado al territorio y contexto transal-

${ }^{1}$ Disponible en http://senato.archivioluce.it/senato-luce/scheda/video/IL3000095749/1/Vita-efine-della-San-Giorgio.html [última consulta: 30/06/2016].

${ }^{2}$ Disponible en http://senato.archivioluce.it/senato-luce/scheda/video/IL3000052313/1/Ali-fasciste.html [última consulta: 30/06/2016]. 
pino) es esencial, preciso, seco, sin excesos retóricos. De Robertis prefiere mostrar $\mathrm{y}$ no demostrar, en perfecta consonancia con la sensibilidad rosselliniana (Aprà 2010: 69-70). Finalmente la buena factura formal (y ciertas presiones de Vittorio Mussolini) convencen a la Scalera film (la más prestigiosa casa de producción italiana organizada a imitación de las majors estadounidenses) a distribuir la película. La visión en la sala de Uomini su fondo, proyectado en las mismas condiciones que películas de ficción, hacía resaltar la inmediata sensación de verosimilitud de los escenarios auténticos (como el interior de un submarino) y la sincera e ingenua actuación de los intérpretes no profesionales. El éxito de la película (estrenada a principios de 1941) convence a Scalera Film para apoyar los dos siguientes proyectos del capitán De Robertis: La nave bianca y Alfa Tau! En este último el comandante pensaba volver a celebrar el heroísmo de una tripulación de submarino; el primero, en cambio, debía ser originariamente un cortometraje ilustrativo sobre el precioso trabajo de un barco hospital. La intervención de la productora permite expandir el proyecto a largometraje. El consecuente aumento de trabajo por De Robertis y una repentina enfermedad obligan al director general de la productora, Massimo Ferrara Santamaria, a buscarle un colaborador. El elegido es Rossellini, que ya figuraba en la plantilla de la productora. Con sus cortometrajes animalistas y minimalistas había ilustrado sus capacidades de realizar trabajos interesantes con medios muy modestos. Su habilidad para encontrar soluciones alternativas in situ garantizaba la solvencia del proyecto frente a la organización de De Robertis: analítica (introduce la práctica del storyboard) y pretensiosa (quería un número exagerado de marinos, sin considerar que el país estaba en guerra). Rossellini asume la consigna del comandante (que de todos modos queda como coguionista y supervisor del proyecto) respetando sus líneas de principio: escasa importancia a la retórica patriótica; uso de intérpretes auténticos que aumentaba exponencialmente el nivel de verosimilitud y reforzaba el sentimiento de pertenencia a toda una comunidad en guerra; y finalmente la adopción de una estructura narrativa flexible que permitía digresiones didácticas sobre los elementos tecnológicos. Esta organización dúctil se explicita foralmente en una construcción binaria del argumento: dos partes que relatan un episodio de batalla marina y el largo proceso de socorro, la terapia y la curación de los marineros heridos.

Primera parte. Italia está en guerra. En un momento de tregua, los marineros de una nave leen la correspondencia. Augusto Basso intercambia cartas con Elena Fondi, una chica a la que nunca ha visto. Un día se dan cita, pero en el preciso instante de zarpar, una contraorden impide el encuentro entre los dos jóvenes. La nave entra en combate y Augusto Basso queda gravemente herido. Segunda parte. Junto con otros compañeros Augusto será trasladado a una nave hospital [...]. Una de las enfermeras es Elena Fondi. La chica reconocerá a Augusto por una medalla que lleva al cuello, pero no querrá revelarle su identidad. Un día, cuando los marineros heridos se trasladan a cubierta para saludar a sus compañeros de la nave [...] Elena y Augusto se reconocen. (Quintana 1995: 43)

Ya desde el primer tiempo (y concretamente en la secuencia del combate) Rossellini se distingue del modus operandi derobertisiano. Mientras que en Uomini sul fondo el heroísmo individual tenía más espacio dramático, en La nave bianca la 
atención se concentra en las máquinas: se representan como dispositivos que consiguen absorber el elemento humano en sus cadencias perfectas. Los marineros cargan los cañones al compás del ruido de los motores: sus movimientos confluyen en una acción colectiva. Desaparecen los personalismos, desvanece el aura mítica del héroe individual. Rossellini intuye que para ganar una guerra moderna no es suficiente el valor de los soldados, no cuenta su audacia. Lo que prevalece son las potencialidades tecnológicas, las competencias profesionales, el peso industrial (Argentieri 1998:122). La guerra, a simple vista, casi no se ve: el enemigo está muy lejos, las dianas se pierden en el horizonte. Las únicas secuencias de combate provienen de escenas de repertorio (según una práctica que el cineasta romano repetirá en muchas de sus películas posteriores). Son desmontadas y remontadas siguiendo un ritmo frenético que remite directamente a la lección eisensteiniana de El Acorazado Potemkin (1925): no es difícil individuar incluso toda una serie de encuadres de la nave de batalla que son directos homenajes a la obra maestra del cineasta soviético. $\mathrm{Y}$, al igual que este último, Rossellini pone en el centro de la representación al grupo. Su interés se dirige hacia los más débiles, los subalternos, los marineros que siempre son víctimas, sea cual sea el resultado del combate.

Esta visual atrae, como un punto de fuga, el desarrollo narrativo de la segunda parte de La nave bianca donde finalmente aparece el barco homónimo. Rossellini elige como personaje principal al individuo más inerme, el marinero peor herido. $\mathrm{Su}$ forzado al inmovilismo ilustra clarísimamente la función metonímica de representante de los últimos. Y todos los otros marineros hospitalizados siguen la evolución de la terapia de su conmilitón y su contemporánea historia de amor con una madrina de guerra, enfermera alistada en la Cruz Roja. Un affaire folletinesco que nace de una correspondencia epistolar y sigue con toda una serie de desencuentros. Están uno al lado del otro, pero no se conocen. La guerra y el destino aplazan hasta el final el reconocimiento, manteniendo viva la conmoción del público.

La nave bianca es una película que vehicula su eficacia en la directa participación de los espectadores. Todo el público se dispone a sufrir con los personajes porque conoce aquello que los personajes no saben, porque organiza con extrema pericia las situaciones emotivas. Un gran éxito. (Masi y Lancia 1987: 13)

La elección de este tratamiento melodramático denota el respeto del autor por el sufrimiento coral. La coparticipación de Rossellini, todavía no problematizada pero sincera, a la tragedia colectiva de la guerra. No quiere indicar las causas; tampoco tendría, en 1941, la posibilidad, ni los instrumentos. Su principal intención es la de expresar, de manera eficaz, su profundo sentimiento de solidaridad. Una conmoción auténtica, dentro y fuera de la pantalla, que, en una futura óptica neorrealista, tenderán a coincidir.

\section{Pródromos del neorrealismo: conclusiones}

La nave bianca gana la Copa del Partido Nacional Fascista (el premio especial del jurado) en la IX Muestra Internacional de Arte Cinematográfica de Venecia (sep- 
tiembre 1941). Los críticos de la revista Cinema (receptáculo de futuros paladinos neorrealistas) lo saludan como testimonio del nuevo curso de la escuela documental italiana: «un film donde las originarias intenciones propagandísticas se subliman en las formas del arte y de la belleza» (Isani 1941: 236). La estructura discursiva binaria de La nave bianca constituía un motivo formal totalmente inusual. Su heterogeneidad expresiva mal se acompañaba de un discurso de propaganda que, en su intención persuasiva, debía poseer necesariamente una unidad granítica. La discontinuidad dramatúrgica anticipa el estilo aparentemente improvisado, el modo anti convencional de juntar ambientes, fragmentos de narración, impresiones: un pródromo del modelo de cine abierto que caracterizará su producción madura (Rondolino 2006: 50). En esta ausencia de prejuicio, este interés inductivo hacia la realidad en su directo devenir cambia la perspectiva hermenéutica a los pocos elementos propagandísticos presentes en la película. Se oye a los oficiales y a los marineros pronunciar eslóganes fascistas: «¡Viva el rey! ¡Saludos al duce!»; en las paredes aparece el retrato del duce (a la derecha de Vittorio Emanuele III); en la misma nave está pintado el famoso lema mussoliniano «el que duda está perdido». Son todos detalles que pertenecen a la genuina representación de la realidad. Utilizarlos como muestras de una afiliación (aunque oportunista, tibia o implícita) a la ideología fascista representa una manipulación, una valoración cercana al error, al falso histórico. Es cierto que el supervisor de la película, el comandante De Robertis, era declaradamente fascista y como tal se mantendrá, tras el 8 septiembre 1943, alistándose en la Reppublica di Salò. Pero su idea de cine (en la cual se insertan las experimentaciones de la fresca sensibilidad rosselliniana), más que un rechazo ideológico, debería suscitar una reflexión sobre el cine italiano entre finales de los años treinta y principios de los cuarenta: una filmografía suspendida en un limbo donde confluyen fascismo y neorrealismo, modernidad y conservadurismo, realismo y géneros. Recuerda el historiador Zagarrio (2004: 192) que hay que considerar a De Robertis un pionero, un precursor del nuevo clima cinematográfico posbélico, a pesar de su declarada afiliación ideológica: no es un caso que con el proyecto de La nave bianca apadrine a Rossellini.

En esta dirección es más productivo pensar que La nave bianca es la síntesis dialéctica entre dinámicas autorales y contexto político, sello de fábrica superficial y poética individual. Es más fructífero considerarlo como texto que intenta prescindir del contingente cotidiano. Primera etapa de una búsqueda de una realidad histórica más transversal y profunda, una verdad personal, líricamente íntima, espiritual. Una ópera prima donde confluyen las investigaciones artesanales e intelectuales de los cortometrajes alegóricos. Experimentaciones sobre la posibilidad de connotar trágicamente elementos narrativos mínimos: ejemplos de cómo el entorno prosaico del día a día puede despertar emociones. Averiguación del dramatismo presente en los acontecimientos pequeños, imperceptibles a simple vista. Interés por todos los otros, los humiles, especialmente los olvidados, la humanidad que vive, trabaja y sufre silenciosa. El sentido más profundo es ilustrar la historia de seres humanos sin historias que se convierten en motores de la Historia. Anticipación directa del principio ético neorrealista y eje de la entera filmografía rosselliniana: su alma, su núcleo religioso. Una espiritualidad detectada y descrita por su hermano, autor de las bandas sonoras de sus películas a partir, precisamente, de La nave bianca: 
La poesía de tu narrar, tu mirada cariñosa hacia las grandes pasiones de pequeños hombres, con un alma simple, recuerdan los juegos tiernos de nuestra infancia, nuestros hábitos, nuestros antiguos y eternos ideales. Y mientras que yo me estaba perdiendo en un mar de notas melancólicas, tú empezabas un largo camino de afanosas experiencias. Laboriosa búsqueda de un ideal donde placar tu ánimo inquieto y descontento. (Rossellini, Renzo 1943: 62)

\section{Referencias bibliográficas}

APRÀ, Adriano (2010): «Storie di guerra: De Robertis e Rossellini», en Ernesto G. Laura (ed.): Storia del cinema italiano 1940/1944, pp. 69-88. Venezia: Marsilio.

ARGENTIERI, Mino (1998): Il cinema in guerra. Arte, comunicazione e propaganda in Italia 1940-1944. Roma: Editori Riuniti.

- (2003): L'occhio del regime. Roma: Bulzoni.

BALDELl, Pio (1972): Roberto Rossellini, i suoi film, 1936-1972, e la filmografia completa: dibattiti e intervista al regista. Roma: Ediz. Samona e Savelli.

DE RoBertis, Francesco (1949): «Libertas, Unitas, Caritas». Cinema I, 7: 212.

CAMINATI, Luca (2012): Roberto Rossellini documentarista. Una cultura della realtà. Roma: Carrocci.

FALDINI, Franca y FofI, Goffredo (2009): L'avventurosa storia del cinema italiano da la Canzone dell'amore a Senza pietà. Bologna: Edizioni della Cineteca.

ISANI, Giuseppe (1941): «Film di questi giorni». Cinema IV, 127: 236.

MASI, Stefano y LANCIA, Enrico (1987): I film di Roberto Rossellini. Roma: Gremese Editore.

Mosconi, Elena (2006): «Goffredo Alessandrini», en Orio Caldiron (ed.): Storia del cinema italiano 1934/1939, pp. 236-244. Venezia: Marsilio.

QuintanA, Ángel (1995): Roberto Rossellini. Madrid: Cátedra.

RONDOLINO, Gianni (2006): Rossellini. Torino: UTET.

Rossellini, Renzo (1943): «Schermi sonori: Al fratello». Cinema ISANI, Giuseppe (1941): «Film di questi giorni». Cinema VIII, 158: 62.

Rossellini, Roberto (2006): Il mio método. Scritti e interviste. Venezia: Marsilio.

SAVIO, Francesco (1979): Cinecittà anni trenta: parlano 116 protagonisti del secondo cinema italiano (1930-1943), III. Roma: Bulzoni.

VERdOne, Mario y RosselLinI, Roberto (1952): «Colloquio sul Neorealismo». Bianco e Nero XIII, 2: 7-16.

ZAGARrIO, Vito (2004): Cinema e Fascismo. Film, modelli, immaginari. Venezia: Marsilio. 